\title{
Chromium-based metal organic framework for pipette tip micro-solid phase extraction: an effective approach for determination of methyl and propyl parabens in wastewater and shampoo samples
}

Massoud Kaykhaii ${ }^{1} 4^{*}$, Sayyed Hossein Hashemi ${ }^{2}$, Fariba Andarz ${ }^{1}$, Amin Piri ${ }^{1}$ and Ghasem Sargazi ${ }^{3}$

\begin{abstract}
Background: A chromium-based metal organic framework was synthesized and employed as an efficient sorbent for pipette tip micro-solid phase extraction and preconcentration of parabens from wastewater and shampoo samples up to sub-ppb level before their spectrophotometric analysis.

Results: Factors affecting preconcentration including volume and type of solvent, amount of sorbent, number of extraction, and volume and $\mathrm{pH}$ of samples were optimized employing one-variable-at-a-time and response surface methodology. Obtained analytical characteristics of the method proves its usefulness for analysis of real samples. Linear range of the method for parabens was $1.0-200.0 \mu \mathrm{g} / \mathrm{L}$. Detection limit of the protocol was $0.24 \mu \mathrm{g} / \mathrm{L}$ for propyl paraben and $0.25 \mu \mathrm{g} / \mathrm{L}$ for methyl paraben. Reproducibility of the protocol defined as \% RSD was better than $5.78 \%$. Synthesized adsorbent can be re-used for at least 20 extractions.
\end{abstract}

Conclusion: The method showed a good detection limit and precision for determination of methyl- and propylparaben in wastewater and shampoo samples.

Keywords: Paraben, Pipette tip micro solid phase extraction, Sample preparation, Metal organic framework, Response surface methodology, Spectrophotometry

\section{Introduction}

Parabens are esters derived of $p$-hydroxybenzoic acid with antimicrobial properties which are in use as preservatives in personal care products, especially shampoos to prevent fungal and microbial infections. It is estimated that up to $90 \%$ of cosmetics contain parabens at levels of $0.01-0.3 \%$ [1]. The most common parabens that exist in

*Correspondence: kaykhaii@chem.usb.ac.ir

1 Department of Chemistry, Faculty of Sciences, University of Sistan and Baluchestan, Zahedan 98136-674, Iran

Full list of author information is available at the end of the article cosmetics are methylparaben (MP), propylparaben (PP), ethylparaben and butylparaben. Paraben mixtures are generally added to cover a general antimicrobial spectrum because some of them have selective activity [2].

Wastewater consists of a vast variety of chemicals emerging pollutants. One of them are parabens which may enter to wastewater from personal care products, especially shampoos, and ultimately can contaminate environment. Parabens can also be released into water ecosystems mainly from personal care production plant discharges. Exposure to these compounds may cause decreased hatching in birds, fish and turtles, feminization 
of male fish, reptiles, birds and mammals; and changes in the immune system of marine mammals; and changes in the immune system of marine mammals because of their bioaccumulation potential. The con increase breast cancer incidence interferes in male reproductive functions and influence malignant melanoma development that exhibits to be influenced using estrogenic stimulation [3, 4].

Several analytical techniques were used for the analysis of parabens in cosmetics and aquatic samples, including: high performance liquid chromatography ultraviolet detection (HPLC-UV) [1, 5], gas chromatography [6], gas chromatography-mass spectrometry [7] and capillary electrophoresis [8, 9]. Because of low concentration of these substances and complexity of media, a sample enrichment/extraction step is indispensable. Solid phase extraction (SPE) [8], ultrasonic nebulization extraction assisted dispersive liquid-liquid microextraction [10], solid phase microextraction [11], dispersive liquid-liquid microextraction [12], matrix solid phase dispersion [13] and magnetically assisted matrix solid phase dispersion [14] are some advanced techniques which have been introduced for enrichment of parabens from different real samples. However, most of them are time consuming, multi-step, need large volumes of samples and adsorbent or they are not economical.

In the sense, modern SPE versions have introduced to miniaturize and simplify the extraction protocols, including pipette tip based micro-SPE ( $\mu$ SPE), because of its inherent advantages which consist of ease of use, reduced solvent consumption and sample volume and high sample throughput applying either multi-channel hand pipettes or robotic liquid handling system [15-22].

Metal organic frameworks (MOFs) are classified as extremely ordered crystalline metal clusters with high porosity $(>90 \%)$ and extremely large surface area (up to $7410 \mathrm{~m}^{2} / \mathrm{g}$ ), consist of metal-oxide clusters and organic linkers. The variation of metal oxides and the proper selection of organic linkers allow the pore size, volume, and functionality to be tailored for designable applications. Also, the characteristics of MOFs is mainly based on the nature of the selected inorganic and organic nodes and ligands and their connectivity [23]. Owing to their fascinating structures and abnormal properties, including permanent nanoscale porosity, high surface, uniform structure cavities and good thermostability, they found many applications in chemical analysis, mainly as extracting media [24]. MOFs has found some novel application such as extraction of cyanide from different water samples by porous copper based MOF modified with carbon paste electrode [25].

Response surface methodology (RSM) can be summarized as a compilation of statistical tools and procedure for constructing and obtaining function relationship between a response variable and set of design variable. It is the collection of mathematical and numerical techniques that are enough for modelling and analysis of the problems having numerous variables influencing the absorbance as response, and objective is to investigate the response. The most extensive application of RSM can be found in industrial world, where a number of input variables affect some performance determines, named the response, in ways that are not easy or unfeasible to depict using a rigorous mathematical formulation [26, 27].

The aim of this paper is to present a simple, selective, fast and sensitive method for the extraction and preconcentration of MP and PP from wastewater and shampoo samples using a novel metal organic frameworks pipette tip micro-solid phase extraction (MOF PT- $\mu \mathrm{SPE}$ ). A regular spectrophotometer was employed for quantitative analysis. The protocol was optimized utilizing one-variable-at-a-time and RSM.

\section{Experimental}

\section{Apparatus}

Spectrophotometric determinations were performed on a PerkinElmer model Lambda 25 double beam spectrophotometer (US) at a wavelength of $255 \mathrm{~nm}$ for both parabens. Microcells with $20 \mu \mathrm{L}$ capacity were employed. For $\mathrm{pH}$ adjustments, a Metrohm (Switzerland) $\mathrm{pH}$ meter model 713 was employed. For qualitative spectral interpretation and structural elucidation of MOFs, Fourier transform infrared (FTIR) spectrometer (Bucks, UK) was used. A Bruker (model D8 Advance, Germany) was employed for powder X-ray diffraction (XRD) measurements. The morphology of MOFs was investigated using a scanning electron microscope (SEM), model MIRA3 TESCAN (Czech Republic).

\section{Reagents}

All chemicals were of analytical grade (Merck KGaA, Darmstadt, Germany) with high purity and applied as received. Purity of main reagents such as 2,6-pyridine dicarboxylic acid and $\mathrm{Cr}\left(\mathrm{NO}_{3}\right)_{3} \cdot 4 \mathrm{H}_{2} \mathrm{O}$ were $99 \%$. During all experiments, ultra-pure water (18.2 $\mathrm{M} \Omega$ ), purified by MilliQ-Millipore system (Millipore, Germany) 
was used. Fresh stock standard solutions of $100 \mathrm{mg} / \mathrm{L}$ of the parabens was made daily by dissolving $100 \mathrm{mg}$ of the reagents in $1000 \mathrm{~mL}$ of water, that was maintained away from light in a refrigerator. Working standard solutions were achieved by dilution of these stock solutions before analysis.

\section{Synthesis of Cr-MOF adsorbent}

Microwave technique was used to prepare this novel CrMOF adsorbent for the first time. At first, $0.02 \mathrm{~mol}$ of $\mathrm{Cr}\left(\mathrm{NO}_{3}\right)_{2}$ and $0.06 \mathrm{~mol}$ of pyridine-2,6 dicarboxylic acid $(0.06 \mathrm{mmol})$ ligand were separately dissolved in $25 \mathrm{~mL}$ of water. Ligand solution was slowly added to the chromium nitrate and mixture was stirred approximately $40 \mathrm{~min}$ at $85{ }^{\circ} \mathrm{C}$. In the next step, the Cr-MOF sample nanostructures were entered into a microwave reactor and placed under the optimal irradiation with the microwave power of $600 \mathrm{~W}$ for $10 \mathrm{~min}$ at the ambient temperature. After cooling to room temperature crystals of porous $\mathrm{Cr}-\mathrm{MOF}$ were formed, which was washed with distilled water and separated by filtration.

\section{Extraction procedure}

In order to prepare a column for pipette tip micro-solid phase extraction, the suitable amount of the MOF was packed loosely in a pipette-tip as discussed in one of our previous papers [28]. Cotton was put at both ends of the tip to avoid adsorbent loss. Before the first use, this column was washed ten times by $10.0 \mathrm{~mL}$ portion of ultrapure water using a commercial syringe. For the purpose of optimization of the extraction, a $34.0 \mathrm{~mL}$ aliquot of sample $(\mathrm{pH}=7.0)$ was spiked by paraben to make a $180.0 \mu \mathrm{g} / \mathrm{L}$ solution of each analyte and $100 \mu \mathrm{L}$ of it was loaded to the tip 7 times. Then, the analyte were eluted by $100 \mu \mathrm{L}$ of chloroform (eluent solvent) for 4 times. Each time, the eluent was recycled to the same vial. Finally, $15 \mu \mathrm{L}$ of the desorbed analytes were transferred to a quartz micro-cell and determined by a spectrophotometer.

\section{Preparation of real samples}

In order to assess the applicability of suggested protocol to real samples in a complicated matrix, it was applied to extract and enrich MP and PP in wastewater and shampoo samples. Wastewater taken from the sewage of the University of Sistan and Baluchestan. It was filtered through a filter paper before extraction to be free from suspending particles. For shampoo sample, $0.3 \mathrm{~g}$ of it was weighed in a flask and dissolved in $100 \mathrm{~mL}$ ultrapure water. Next, $25 \mathrm{~mL}$ of the solution was diluted to

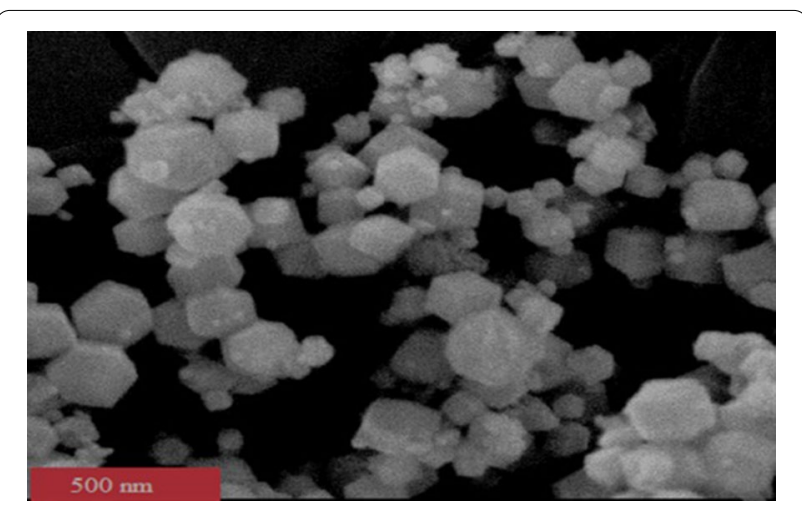

Fig. 1 Scanning electron microscope image of the synthesized Cr-MOF sorbent

$100 \mathrm{~mL}$ and used for PT- $\mu$ SPE. No analytes were found in the selected samples (confirmed by HPLC-UV)-which was also in agreement with composition declared by the shampoo manufacturer.

\section{Results and discussion}

\section{Characterization of the sorbent}

The SEM image of the synthesized Cr-MOF is depicted in Fig. 1. As can be seen, it has a pure uniform size distribution as well as a homogenous morphology and there is no sign of the agglomeration or aggregation in it. The creation of the pores is visible in the image, and the average size of the synthesized Cr-MOF is $50 \mathrm{~nm}$. Using BarrettJoyner-Halenda (BJH) technique, the specific surface area of the sorbent was determined as $2.8 \times 10^{2} \mathrm{~m}^{2} / \mathrm{g}$.

The FTIR spectrum of Cr-MOF is shown on Fig. 2. The broad band in the region of $3500 \mathrm{~cm}^{-1}$ reveals the presence of coordinated water in the structure. Also, wave number values in the regions of $2830 \mathrm{~cm}^{-1}$ and $2995 \mathrm{~cm}^{-1}$ confirmed $\mathrm{CH}_{2}$ aliphatic. In addition, observed bands in the range of 1480 to $1720 \mathrm{~cm}^{-1}$ indicate the presence of $\mathrm{CO}_{2}$ groups related to ionized liquids in the structure. Absorption bands in the range of 680 and $980 \mathrm{~cm}^{-1}$ are assigned to $\mathrm{Cr}-\mathrm{O}$ bond formation and aliphatic $\mathrm{C}-\mathrm{H}$ groups, respectively. The presence of wide peaks shows the nature of $\mathrm{Cr}-\mathrm{MOF}$ is nano-crystalline (confirmed by XRD). Based on the obtained results from the FTIR spectrum as well as the various configurations of 2,6-pyridine dicarboxylic acid ligand, the mechanism of Fig. 3 can be suggested for the formation of products. These reactions continue until it leads to the formation of the final structure of porous $\mathrm{Cr}$-MOF. Figure 4 shows the proposed structure of the synthesized Cr-MOF. Using XRD and SEM data, the average size of $\mathrm{Cr}-\mathrm{MOF}$ 


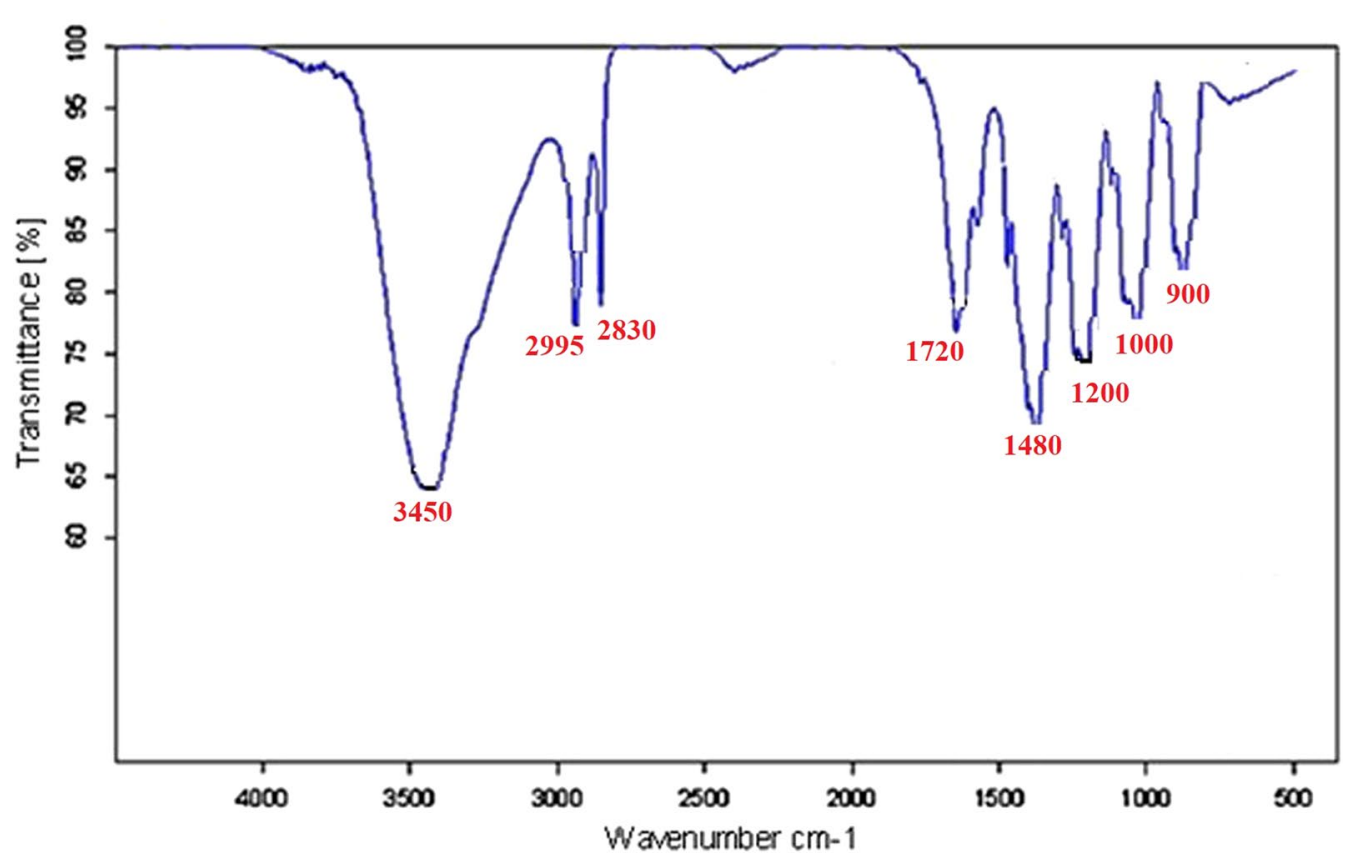

Fig. 2 FTIR spectrum of Cr-MOF sorbent

crystals was found to be about $26 \mathrm{~nm}$. The porosity and pores of the structure volume were calculated using Barrett-Joyner-Halenda (BJH) technique. According to this method, the average pore diameter of the sample is in mesoporous nature (Fig. 5).

\section{Optimization of PT- $\mu$ SPE}

To investigate the parameters affecting PT- $\mu$ SPE of parabens, different factors which potentially could affect the extraction were checked out employing two methods of one-variable-at-a-time and RSM. Aliquots of aqueous standard solution of each analyte at a concentration of $100.0 \mu \mathrm{g} / \mathrm{L}$ were used for optimization experiments. Each run was repeated three times.

\section{Effect of type and volume of eluent solvent}

After extraction of paraben by $\mathrm{Cr}-\mathrm{MOF}$, it is necessary to elute it using a proper solvent that can efficiently desorb the analytes. For selecting the best eluent, a number of common solvents including dichloromethane, carbon tetrachloride, 1,1,2,2-tetrachloroethane, dichloromethane, chloroform, methanol, 1-octanol, 1-hexanol, ethylbenzene, propyl benzene, benzyl alcohol and toluene were examined. Because of the highest analytical signal obtained, chloroform showed the best eluting performance and was selected as the eluent solvent for further experiments. In $\mu$ PT-SPE technique, to achieve the highest efficiency, the volume of the eluting solvent should be kept in minimum; however, it should provide quantitative desorption of the analytes from the MOF surface. Volume of the eluent solvent, chloroform, was changed in the range of 50 to $400 \mu \mathrm{L}$. The results showed that the best response is achieved at $100 \mu \mathrm{L}$ and after this point the absorbance decreased, probably because of the dilution effect when a greater volume of extraction solvent was used [28].

\section{Number of elution cycles}

The number of cycles of elution step is an important parameter that affects extraction efficiency [29]. The procedure of aspiration of a certain amount of the eluent solvent into the pipette tip and dispensed back into the same solvent tube is called an elution cycle. To investigate this parameter, $100 \mu \mathrm{L}$ of chloroform was applied during cycles of 1 to 8 . The best extraction efficiency was obtained by 4 cycles. Therefore, the number of elution cycles was selected 4 for the next experiments.

\section{Response surface methodology}

An optimization process was carried out to select the best experimental conditions for $\mu \mathrm{SPE}$ of parabens with 


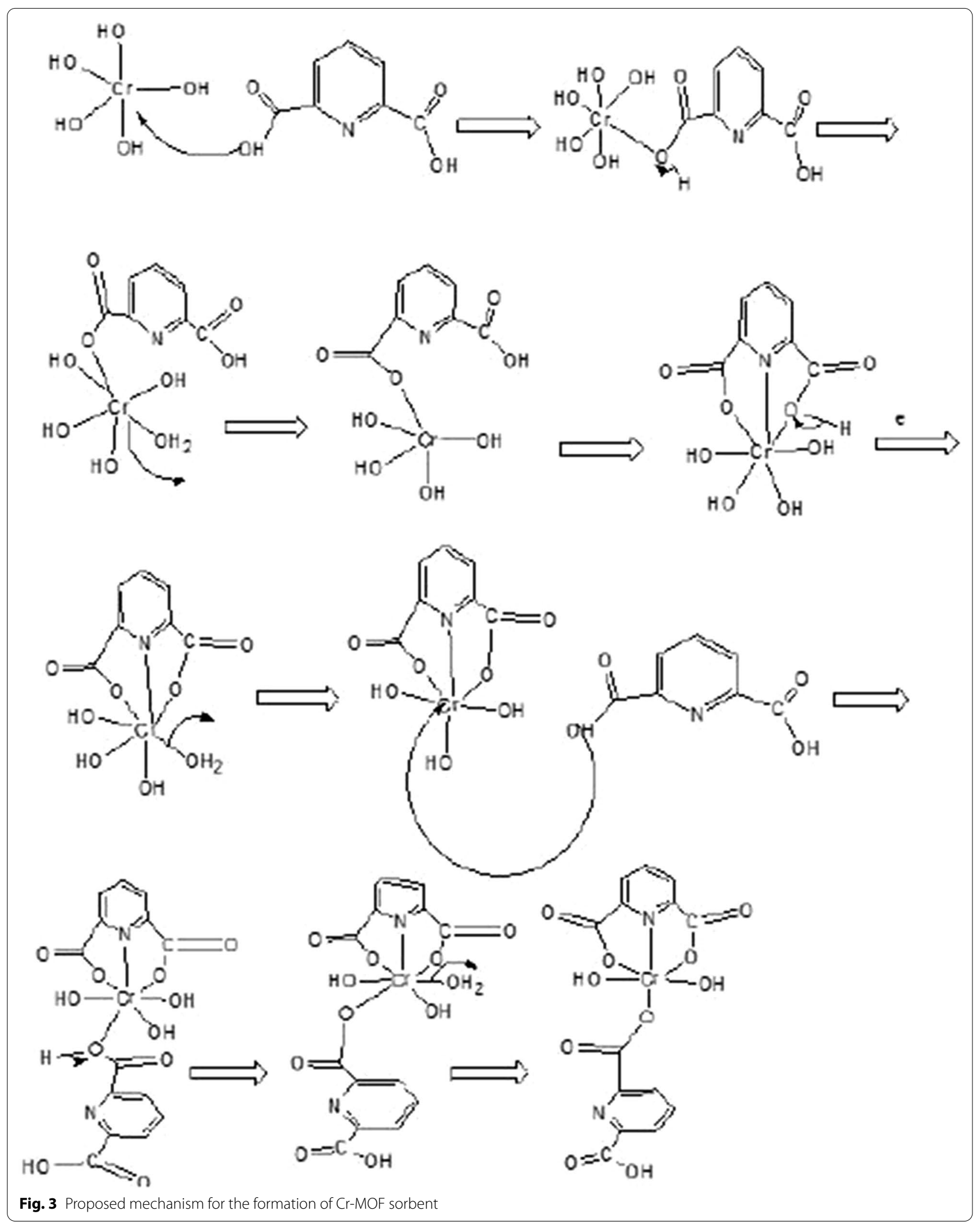


RSM. RSM is a type of experimental design protocols to obtain an optimal extraction efficiency [30]. In this research, significant variables are assumed to be $\mathrm{pH}$ (A or $\mathrm{X}_{1}$ ), number of cycles of extraction (B or $\mathrm{X}_{2}$ ), volume of sample solution $\left(\mathrm{C}\right.$ or $\mathrm{X}_{3}$ ) and amount of sorbent $(\mathrm{mg})(\mathrm{D}$ or $\mathrm{X}_{4}$ ). The $\mathrm{pKa} \mathrm{MP}$ and $\mathrm{PP}$ are 8.2 and 8.4, respectively. To extract these compounds efficiently, the $\mathrm{pH}$ of the sample should be controlled to keep the selected compounds in their molecular state, that beneficial for extraction [5]. The low, middle and high levels of each factor were explained as $-1,0,+1$, respectively. In Additional file 1: Table $\mathrm{S} 1$, the actual design of runs is explained.

In a system consist of four significant variables, $A\left(X_{1}\right)$, $\mathrm{B}\left(\mathrm{X}_{2}\right), \mathrm{C}\left(\mathrm{X}_{3}\right)$ and $\mathrm{D}\left(\mathrm{X}_{4}\right)$, the mathematical relationship of the response on these variables can be approximated using quadratic (second degree) polynomial equation (Eq. 1):

$$
\mathrm{Y}=\beta_{0}+\sum \beta_{\mathrm{i}} \mathrm{X}_{\mathrm{i}}+\sum \beta_{\mathrm{ii}} \mathrm{X}_{\mathrm{ii}}+\sum \beta_{\mathrm{ij}} \mathrm{X}_{\mathrm{i}} \mathrm{X}_{\mathrm{j}}+\mathrm{e} .
$$

In Eq. $1, Y$ is predicted response, $\beta_{0}$ is the constant, $X_{1}$, $\mathrm{X}_{2}, \mathrm{X}_{3}$ and $\mathrm{X}_{4}$ are the coded independent variables, $\beta_{\mathrm{i}}$ is the linear effect, $\beta_{\mathrm{ii}}$ is the quadratic effect, $\beta_{\mathrm{ij}}$ proved the coefficient of the interaction factor, and $\mathrm{e}$ is the random error or allows for description or uncertainties between predicated and achieved data [31]. Equation 2 shows the mathematical relationship of the analytical signal and four indicated variables.
By solving these equation systems for the condition of $\partial(\mathrm{Y}) / \partial(\mathrm{A})=0, \partial(\mathrm{Y}) / \partial(\mathrm{B})=0, \partial(\mathrm{Y}) / \partial(\mathrm{C})=0$ and $\partial(\mathrm{Y}) / \partial(\mathrm{D})=0$, the critical point in the surface can be obtained [32]. In Additional file 1: Table S2, the summary of analysis of variance (ANOVA) is presented.

The achieved data for critical paint are as follows: $\mathrm{pH}(\mathrm{A})=7$, number of cycles of extraction $(\mathrm{B})=7$, volume of sample solution $(\mathrm{C})=34 \mathrm{~mL}$ and amount of sorbent $=7 \mathrm{mg}$. The regression model for the analytes resulted in a determination coefficient $\left(R^{2}=0.9876\right)$, explaining that only $1.24 \%$ of the variation cannot be described with this model. The adjusted $R^{2}=0.9744$ confirmed that this model was highly significant. Additionally, the prediction $\mathrm{R}^{2}$ of 0.9265 was an inacceptable agreement level of $\mathrm{R}^{2}$, thus the obtained prediction has a very good effectiveness. The F-value of model shows that the model is significant (Additional file 1: Table S2). A p-value lower than 0.0001 was found, demonstrating again the high significance of the regression models. A p-value less than 0.05 in the ANOVA table statistical significance of an effect at $95 \%$ confidence level. The F-value of Lack of fit (LOF) of 5.54 explained that the parameter was not significant relative to the pure errors. The small difference between the data predicted using the model and the experimental result, the analysis of variance of the model were highly satisfactory. The ANOVA of the regression model expressed that the quadratic model was significant, as was evident utilizing a very low probability

$$
\begin{aligned}
R= & (-0.619)+(0.0400 \times A)+(0.0919 \times B)+(0.04318 \times C)+(0.1763 \times D)-\left(0.01359 A^{2}\right) \\
& -\left(0.01139 B^{2}\right)-\left(0.000644 C^{2}\right)-\left(0.01777 D^{2}\right)+(0.00485 A \times B)-(0.000233 A \times C)+(0.00997 A \times D) \\
& +(0.000640 B \times C)+(0.00017 B \times D)+(0.000262 C \times D) .
\end{aligned}
$$

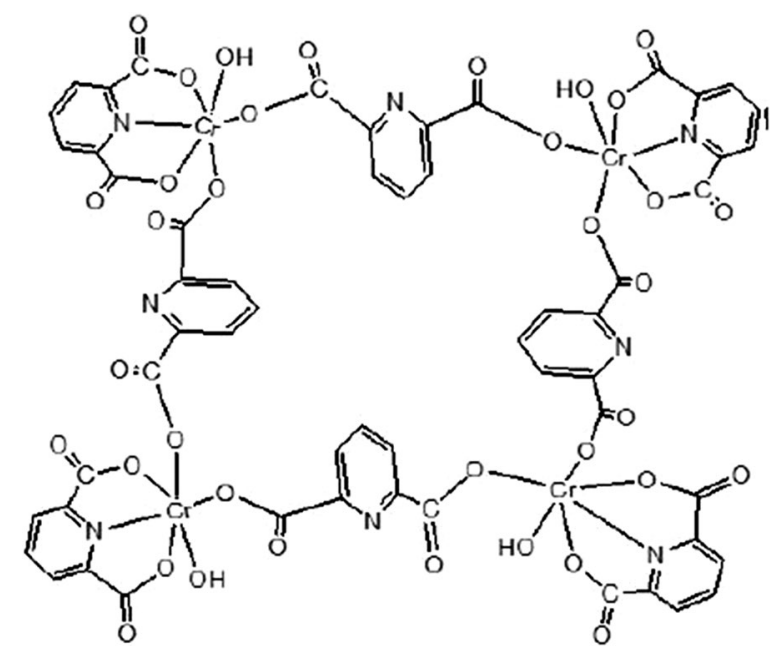

Fig. 4 The proposed structure related to formation of the $\mathrm{Cr}-\mathrm{MOF}$ sorbent value $(p)\left(p_{\text {model }} \leq 0.0001\right)$. Response surface-2D/contours explain the effect of independent variable on response of parabens (Fig. 6).

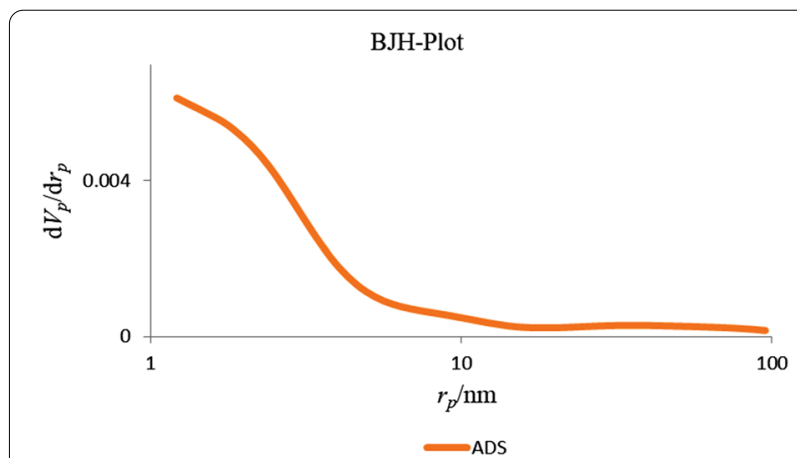

Fig. 5 BJH pore size distribution of $\mathrm{Cr}-\mathrm{MOF}$ nanostructures 


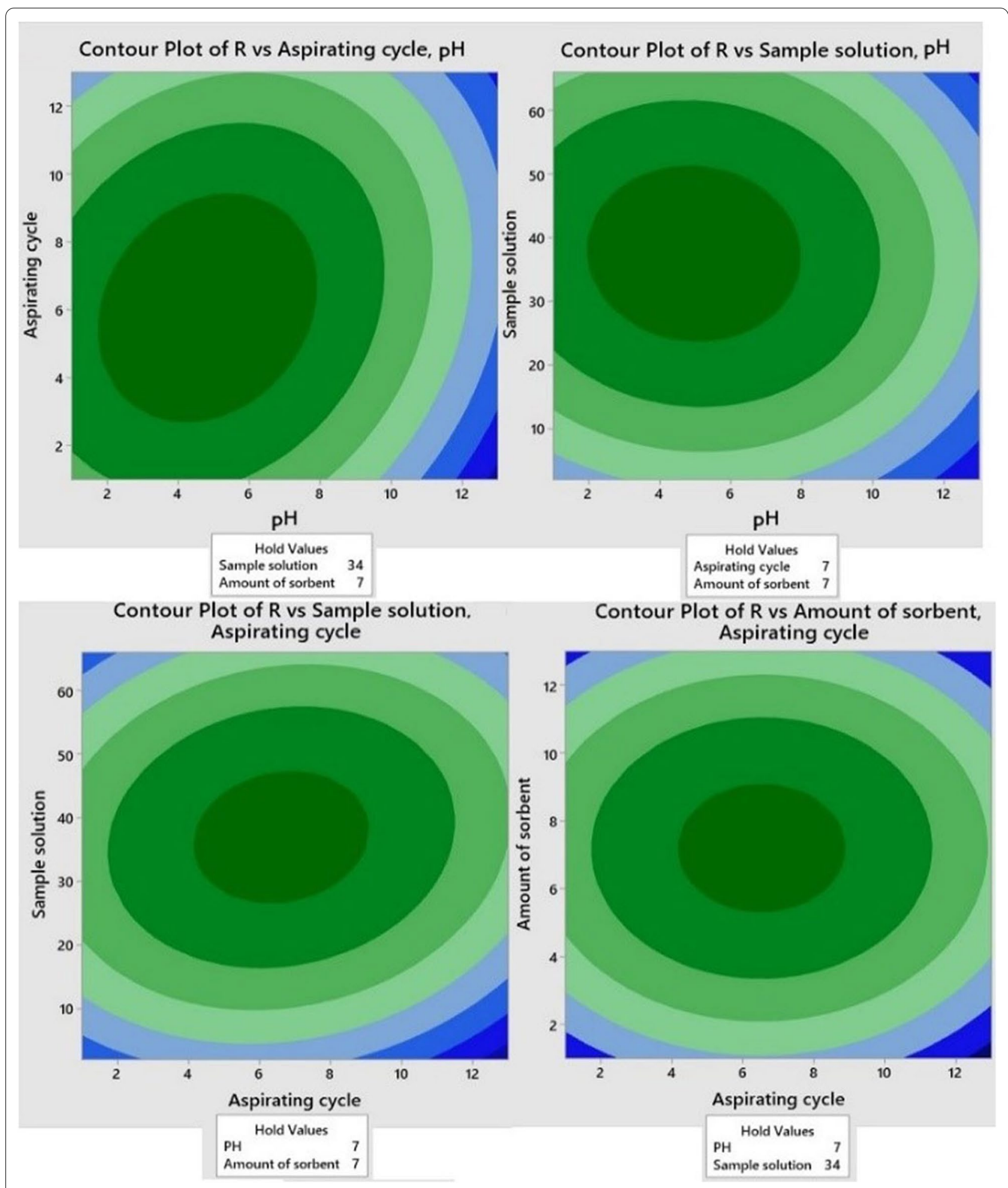

Fig. 6 Response surface-2D/contours explaining the effect of independent variable on response (absorbance) of parabens 
Table 1 Comparison of the published protocol for MP and PP parabens determination with proposed technique in the research

\begin{tabular}{|c|c|c|c|c|c|c|c|}
\hline Sample & Analyte(s) & $\begin{array}{l}\text { Extraction } \\
\text { method }\end{array}$ & Instrument & $\operatorname{LOD}(\mu \mathrm{g} / \mathrm{L})$ & $\mathrm{LOQ}(\mu \mathrm{g} / \mathrm{L})$ & $\begin{array}{l}\text { Linear range } \\
(\mu \mathrm{g} / \mathrm{L})\end{array}$ & Refs. \\
\hline $\begin{array}{l}\text { Water, cosmetic } \\
\text { creams, human } \\
\text { urine }\end{array}$ & $\begin{array}{l}\text { Methyl, ethyl, } \\
\text { propyl, isopropyl, } \\
\text { butyl and isobutyl } \\
\text { and benzyl } \\
\text { paraben }\end{array}$ & SPME & HPLC- UV & $1.5-2.6$ & $5.0-8.7$ & $0.5-147.0$ & [1] \\
\hline Human urine & $\begin{array}{l}\text { Methyl, ethyl, } \\
\text { propyl and butyl } \\
\text { paraben }\end{array}$ & SPME & HPLC- UV & $0.03-0.04(\mu \mathrm{g} / \mathrm{g})$ & $0.40-0.97(\mu \mathrm{g} / \mathrm{g})$ & $0.10-10.00(\mu \mathrm{g} / \mathrm{g})$ & {$[5]$} \\
\hline $\begin{array}{l}\text { River water, } \\
\text { mouthwash, hand } \\
\text { cream }\end{array}$ & $\begin{array}{l}\text { Methyl, ethyl, pro- } \\
\text { pyl, isopropyl and } \\
\text { butyl paraben }\end{array}$ & SPME & GC & $0.0002-0.0500$ & Not mentioned & $50.0-300.0$ & {$[6]$} \\
\hline $\begin{array}{l}\text { Wastewater and } \\
\text { shampoo }\end{array}$ & $\begin{array}{l}\text { Methyl and propyl } \\
\text { paraben }\end{array}$ & PT- $\mu$ SPE & $\begin{array}{l}\text { Spectrophotom- } \\
\text { eter }\end{array}$ & $0.24-0.25$ & $0.80-0.83$ & $1.0-200.0$ & This work \\
\hline
\end{tabular}

SPME solid phase microextraction, HPLC-UV high performance liquid chromatography-ultraviolet detection, GC gas chromatography

\section{Analytical performance}

\section{Linear range, limit of detection and enrichment factor}

The calibration curves for parabens which were plotted separately indicated good linearity in the ranges of 1.0$200.0 \mu \mathrm{g} / \mathrm{L}$ for Parabens. The equation and regression coefficients were:

$$
\begin{aligned}
& A=0.0099 C(\mu g / L)+0.0283 \quad R^{2}=0.9999 \text { for } M P, \\
& A=0.01 C(\mu g / L)+0.0064 \quad R^{2}=0.9998 \text { for } P P,
\end{aligned}
$$

where $\mathrm{C}$ and $\mathrm{A}$ are the concentration of parabens and analytical signal, respectively.

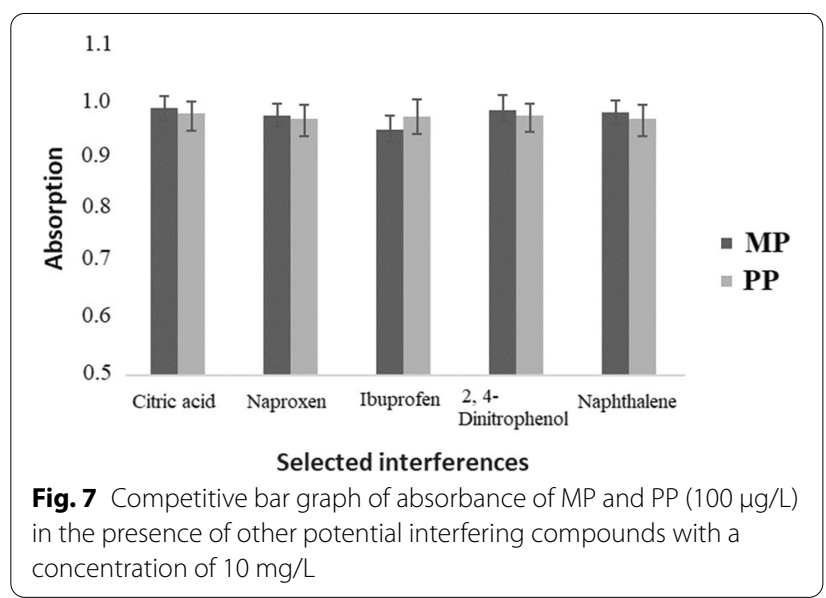

\begin{tabular}{|c|c|c|c|c|c|}
\hline Analyte added & Sample & Analyte added $(\mu \mathrm{g} / \mathrm{L})$ & Analyte found $(\mu \mathrm{g} / \mathrm{L})$ & Recovery & $\operatorname{RSD} \%(n=3)$ \\
\hline \multirow[t]{4}{*}{ MP } & Wastewater & - & - & - & - \\
\hline & & 20 & 19.3 & 96.5 & 1.6 \\
\hline & & 85 & 86.0 & 101.1 & 1.4 \\
\hline & & 140 & 134.0 & 95.7 & 3.6 \\
\hline \multirow[t]{4}{*}{ MP } & Shampoo & - & - & - & \\
\hline & & 20 & 20.0 & 100.0 & 4.1 \\
\hline & & 85 & 87.0 & 102.3 & 3.4 \\
\hline & & 140 & 134.6 & 96.1 & 2.2 \\
\hline \multirow[t]{4}{*}{ PP } & Wastewater & - & - & - & - \\
\hline & & 20 & 20.0 & 100.0 & 2.1 \\
\hline & & 85 & 81.6 & 96.0 & 2.4 \\
\hline & & 140 & 135.0 & 96.4 & 1.9 \\
\hline \multirow[t]{4}{*}{ PP } & Shampoo & - & - & - & - \\
\hline & & 20 & 20.0 & 100.0 & 1.1 \\
\hline & & 85 & 86.6 & 101.9 & 1.3 \\
\hline & & 140 & 133.5 & 95.4 & 2.3 \\
\hline
\end{tabular}

Table 2 Recovery and reproducibility results for determination of parabens achieved for two real samples 
The percent extraction (E\%) of analytes was obtained from the equation $E \%=100\left(C_{B} / C_{A}\right) . C_{A}$ and $C_{B}$ are concentration the analyte in solution before and after extraction, respectively.

The detection limits (LOD) and limit of quantitation (LOQ) of the analytes were calculated based on $3 \mathrm{~S}_{\mathrm{b}} / \mathrm{m}$ and $10 \mathrm{~S}_{\mathrm{b}} / \mathrm{m}$ (In the equation, $\mathrm{S}_{\mathrm{b}}$ is standard deviation of 10 consecutive measurements of the blank extracted with the same procedure and $\mathrm{m}$ is the slope of calibration curve). LODs of $0.25 \mu \mathrm{g} / \mathrm{L}$ and $0.24 \mu \mathrm{g} / \mathrm{L}$ were obtained for MP and PP respectively. LOQs were 0.83 (for MP) and 0.80 (for PP). Considering the final elution volume of $100 \mu \mathrm{L}$ and the sample volume of $34 \mathrm{~mL}$, an enrichment factor (EF) of 340 folds was expected to be achieved, which is close to the EF experimentally observed (330 fold) with an extraction efficiency of $97 \%$. Reproducibility of the protocol as RSD\% $(n=5)$ for concentration of $20 \mu \mathrm{g} / \mathrm{L}$ of the analytes was $2.95 \%$ (for MP) and $5.78 \%$ (for PP). Adsorptive capacity of $200 \mu \mathrm{g}$ of each paraben per $6.0 \mathrm{mg}$ of $\mathrm{Cr}-\mathrm{MOF}$ was achieved for the uptake of both parabens after reaching saturation. Table 1 compares the characteristic data of the present method to those recently reported in the literature for the same analytes.

\section{Repeated usage}

The synthesized Cr-MOF could be reused at least 5 times for the parabens extraction in various samples. It was also kept in dried air for at least 8 months without losing its extraction efficiency. The repeatability between different batches of $\mathrm{Cr}-\mathrm{MOF}(\mathrm{n}=5)$ was achieved to be better than $5.6 \%$.

\section{Selectivity of Cr-MOF toward parabens}

To study the selectivity $\mathrm{Cr}-\mathrm{MOF}$ for the extraction of MP and PP in samples including similar analytes, aliquots of $34 \mathrm{~mL}$ of aqueous sample consist of $100 \mu \mathrm{g} / \mathrm{L}$ of each of the analytes and potential interferences was taken and the selected protocol was performed. Naphthalene, 2,4-dinitrophenol, ibuprofen and naproxen that are normally present in natural sources were chosen for this purpose. No interferences were observed (Fig. 7).

\section{Real samples analysis}

To investigate the effect of sample media on analytical signal, both samples were separately spiked at three concentration levels of 20,85 and $140 \mu \mathrm{g} / \mathrm{L}$ with the selected analytes. Recoveries of parabens from different real samples applying the present technique are showed in Table 2. Recoveries of the analytes were between 95.7 and 102.3\% (for MP) and 95.4-101.9\% (for PP) that indicate negligible effect of the sample matrix on the determination of these analyte with suggested technique. These observations excesses that the suggested procedure can be employed to the analysis of MP and PP in complicated matrices. Figure 8 shows the absorption spectra of extracted wastewater before and after spiking with $85 \mu \mathrm{g} / \mathrm{L}$ of the analytes.

\section{Conclusion}

A new sorbent, Cr-MOF, with a huge surface area was synthesized, characterized and applied for pipette tip micro-solid phase extraction of methyl- and propylparabens in wastewater and shampoo samples with high recovery and low detection limit. No special sample pre-treatment was required and pipette tip column was simply packed with the sorbent and no additional steps were required before passing sample through it. The linear range covers wide concentrations, and $\mathrm{Cr}-\mathrm{MOF}$ could selectively extract parabens for analysis even at the trace concentrations. The adsorbent could be used for at least 20 extractions without substantial change in its adsorption power. The PT-SPE column needs only $6 \mathrm{mg}$ of the sorbent and the total analysis time was less than $6 \mathrm{~min}$. Due to the application of a conventional spectrophotometer and no sample pre-treatment or additional reagents, this method is very simple and extremely economical with easy applicability for routine analysis. 

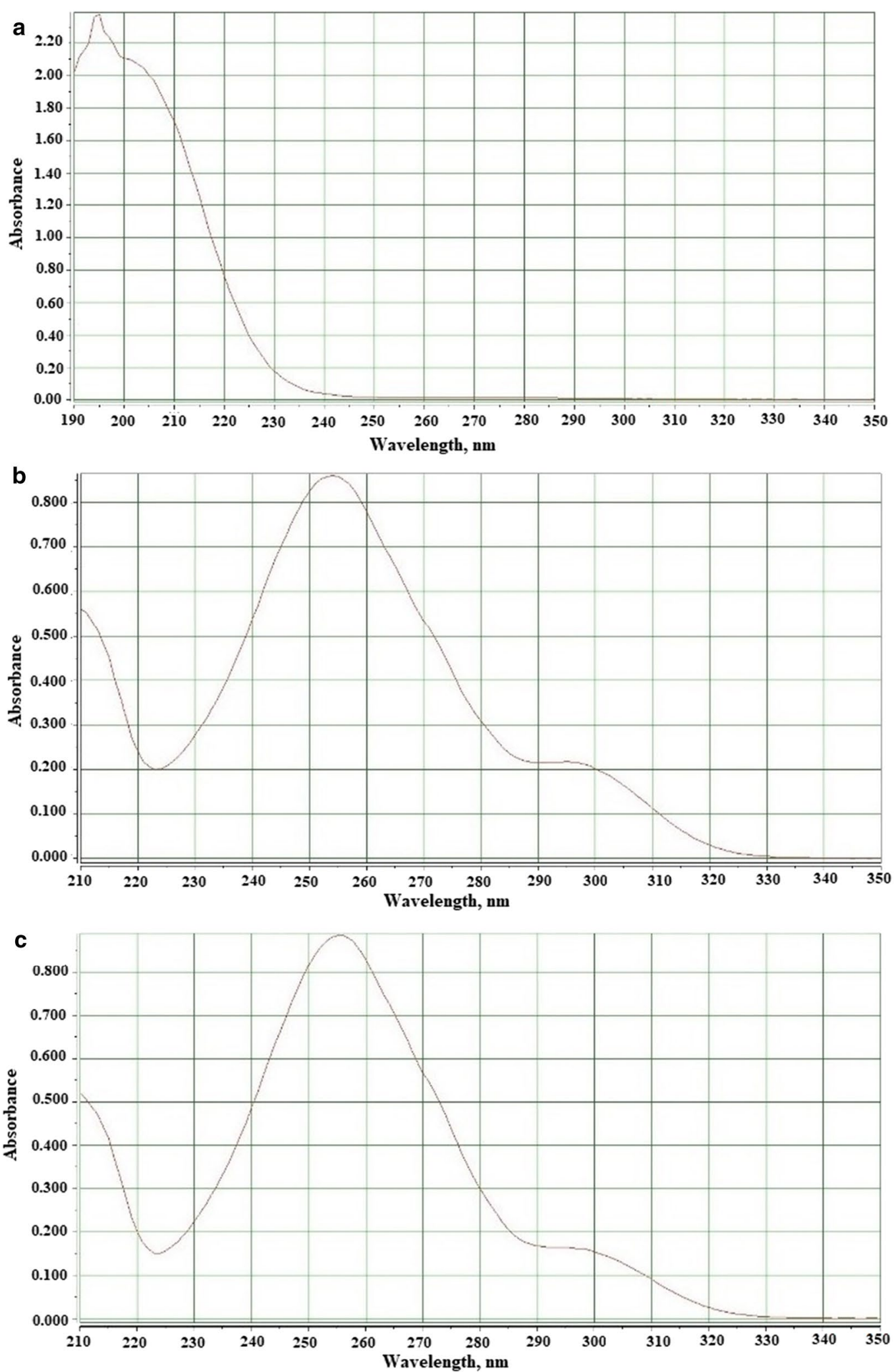

Fig. 8 Absorption spectra of extracted methyl and propyl parabens from wastewater before (a) and after spiking with $85 \mu \mathrm{g} / \mathrm{L}$ of the analytes $(\mathbf{b}$ methyl paraben, c propyl paraben) 


\section{Abbreviations}

MP: Methylparaben; PP: Propylparaben; HPLC-UV: High performance liquid chromatography-ultraviolet; DAD: Diode array detection; UV: Ultraviolet; GC: Gas chromatography; GC-MS: Gas chromatography-mass spectrometry; SPE: Solid phase extraction; MOFs: Metal-organic frameworks; RSM: Response surface methodology; MOF PT- $\mu$ SPE: Metal organic frameworks pipette tip micro-solid phase extraction; XRD: X-ray diffraction; SEM: Scanning electron microscope; ANOVA: Analysis of variance; LOD: Detection limits; EF: Enrichment factor; SPME: Solid phase microextraction; HPLC: High performance liquid chromatography.

\section{Supplementary Information}

The online version contains supplementary material available at https://doi. org/10.1186/s13065-021-00786-7.

Additional file 1: Table S1. Design media in the RSM model for the optimization of $\mathrm{Cr}-\mathrm{MOF}$ PT- $\mathrm{\mu SPE}$. Table S2. Analysis of variance (ANOVA) for parabens.

\section{Acknowledgements}

The authors gratefully acknowledge Research Council of the University of Sistan and Baluchestan, Sistan and Baluchestan Science and Technology Park and Zist Mavad Makkoran 106 Co., Ltd. for their supports. Prof. Massoud Kaykhaii acknowledge Polish National Agency for Academic Exchange (NAWA) under Ulam Programme (Agreement No. PPN/ULM/2020/1/00014/U/ DRAFT/00001)

\section{Authors' contributions}

MK planned the study and wrote the manuscript. SHH co-wrote and updated the manuscript. FA did the practical work. AP did the chemometrics, GS synthesized MOF. All authors read and approved the final manuscript.

\section{Funding}

Not applicable.

\section{Availability of data and materials}

The majority of the data used to support the findings of this study are included within the article. Other data are available from the corresponding author upon request.

\section{Declarations}

Ethics approval and consent to participate

Not applicable.

\section{Consent for publication}

The authors hereby consents to publication of the Work in BMC Chemistry Journal.

\section{Competing interests}

The authors declare that there is no conflict of interests regarding the publication of this paper.

\section{Author details}

'Department of Chemistry, Faculty of Sciences, University of Sistan and Baluchestan, Zahedan 98136-674, Iran. ${ }^{2}$ Department of Marine Chemistry, Faculty of Marine Science, Chabahar Maritime University, Chabahar, Iran. ${ }^{3}$ Nanomaterial Technology Department, Non-Communicable Diseases Research Centre, Bam University of Medical Sciences, Bam, Iran. ${ }^{4}$ Department of Process Engineering and Chemical Technology, Faculty of Chemistry, Gdansk University of Technology, Gdansk, Poland.

Received: 11 August 2021 Accepted: 27 October 2021

Published online: 06 November 2021

\section{References}

1. Rocío-Bautista P, Martínez-Benito C, Pino V, Pasán J, Ayala JH, Ruiz-Pérez C, Afonso AM. The metal-organic framework HKUST-1 as efficient sorbent in a vortex-assisted dispersive micro solid-phase extraction of parabens from environmental waters, cosmetic creams, and human urine. Talanta. 2015;139:13-20.

2. Cabaleiro N, de la Calle I, Bendicho C, Lavilla I. An overview of sample preparation for the determination of parabens in cosmetics. Trends Analyt Chem. 2014:57:34-46.

3. Bila DM, Dezotti M. Desreguladores endócrinos no ambiente: efeitos e consequências. Quim Nova. 2007:30:651-66.

4. Anjos ML, Isique WD, Albertin LL, Matsumoto T, Henares MNP. Parabens removal from domestic sewage by free-floating aquatic macrophytes. Waste Biomass Valoriz. 2019;10:2221-6.

5. Yıldız E, Çabuk H. Miniaturized matrix solid-phase dispersion coupled with supramolecular solvent-based microextraction for the determination of paraben preservatives in cream samples. J Sep Sci. 2018:41:2750-8.

6. Abbasghorbani M, Attaran A, Payehghadr M. Solvent-assisted dispersive micro-SPE by using aminopropyl-functionalized magnetite nanoparticle followed by GC-PID for quantification of parabens in aqueous matrices. J Sep Sci. 2013;36:311-9.

7. Yang TJ, Tsai FJ, Chen CY, Yang TCC, Lee MR. Determination of additives in cosmetics by supercritical fluid extraction on-line headspace solid phase microextraction combined with gas chromatography-mass spectrometry. Anal Chim Acta. 2010;668:188-94.

8. Ye N, Shi P, Li J, Wang Q. Application of graphene as solid phase extraction absorbent for the determination of parabens in cosmetic products by capillary electrophoresis. Anal Lett. 2013;46:1991-2000.

9. Alshana U, Ertaş N, Göğer NG. Determination of parabens in human milk and other food samples by capillary electrophoresis after dispersive liquid-liquid microextraction with back-extraction. Food Chem. 2015:181:1-8.

10. Wei $H$, Yang J, Zhang $H$, Shi Y. Ultrasonic nebulization extraction assisted dispersive liquid-liquid microextraction followed by gas chromatography for the simultaneous determination of six parabens in cosmetic products. J Sep Sci. 2014;37:2349-56.

11. Alvarez-Rivera G, Vila M, Lores M, Garcia-Jares C, Llompart M. Development of a multi-preservative method based on solid-phase microextraction-gas chromatography-tandem mass spectrometry for cosmetic analysis. J Chromatogr A. 2014;1339:13-25.

12. Alshana U, Ertaş N, Göğer NG. Determination of parabens in human milk and other food. Food Chem. 2015;181:1-8.

13. Canosa P, Rodriguez I, Rubi E, Cela R. Determination of parabens and triclosan in indoor dust using matrix solid-phase dispersion and gas chromatography with tandem mass spectrometry. Anal Chem. 2007:79:1675-81.

14. Fotouhia M, Seidia S, Shanehsaz M, Naseri MT. Magnetically assisted matrix solid phase dispersion for extraction of parabens from breast milks. J Chromatogr A. 2017;1504:17-26.

15. Hashemi SH, Kaykhaii M, Keikha AJ, Mirmoradzehi E. Box-Behnken design optimization of pipette tip solid phase extraction for methyl orange and acid red determination by spectrophotometry in seawater samples using graphite based magnetic $\mathrm{NiFe}_{2} \mathrm{O}_{4}$ decorated exfoliated as sorbent. Spectrochim Acta A Mol Biomol Spectrosc. 2019;213:218-27.

16. Hashemi SH, Kaykhaii M, Keikha AJ, Parkaz A. Application of BoxBehnken design in the optimization of a simple graphene oxide/zinc oxide nanocomposite-based pipette tip micro-solid phase extraction for the determination of Rhodamine B and Malachite green in seawater samples by spectrophotometry. Anal Methods. 2018;10:5707-14.

17. Hashemi SH, Kaykhaii M, Keikha AJ, Parkaz A. Application of response surface methodology to optimize pipette tip micro-solid phase extraction of dyes from seawater by molecularly imprinted polymer and their determination by HPLC. J Iran Chem Soc. 2019;16:2613-27.

18. Hashemi SH, Kaykhaii M, Keikha AJ, Sajjadi Z. Application of BoxBehnken design in response surface methodology for the molecularly imprinted polymer pipette-tip solid phase extraction of methyl red from seawater samples and its determination by spectrophotometery. Marine Poll Bull. 2018;137:306-14. 
19. El-Wekil MM, Hassan Refat HA, Marzouk AA, Ramadan A. Enhanced dispersive solid phase extraction assisted by cloud point strategy prior to fluorometric determination of anti-hepatitis $C$ drug velpatasvir in pharmaceutical tablets and body fluids. RSC Adv. 2018;8:13292-300.

20. Hassan Refat HA, Hassan Al, Hassan YF, El-Wekil MM. Mannitol capped magnetic dispersive micro-solid-phase extraction of polar drugs sparfloxacin and orbifloxacin from milk and water samples followed by selective fluorescence sensing using boron-doped carbon quantum dots. J Environ Chem Eng. 2021;9:105078

21. Fardous AM, Pakinaz YK, El-Wekil MM, Shahin RY. Spectrodensitometric determination of rivastigmine after vortex assisted magnetic solid phase extraction. Microchem J. 2019;147:764-74.

22. Bandar AA, Ashraf MM, Alkahtani SA, El-Wekil MM. $\mathrm{NiFe}_{2} \mathrm{O}_{4}$ nanospheres functionalized with 2-(2,4-dihydroxyphenyl)-3,5,7-trihydroxychromen-4-one for selective solid-phase microextraction of aluminium. Talanta. 2021;226:122167.

23. Gutiérrez-Serpa A, Pacheco-Fernández I, Pasán J, Pino V. Metal-organic frameworks as key materials for solid-phase microextraction devicesa review. Separations. 2019;6:47-67.

24. Trujillo-Rodríguez MJ, Pacheco-Fernández I, Taima-Mancera I, Díaz JHA, Pino V. Evolution and current advances in sorbent-based microextraction configurations. J Chromatogr A. 2020;1634:461670.

25. Mahmoud AM, Mahnashi MH, El-Wekil MM. Indirect differential pulse voltammetric analysis of cyanide at porous copper based metal organic framework modified carbon paste electrode: application to different water samples. Talanta. 2021;221:121562.

26. Hashemi SH, Kaykhaii M, Keikha AJ, Mirmoradzehi E, Sargazi G. Application of response surface methodology for optimization of metalorganic framework based pipette-tip solid phase extraction of organic dyes from seawater and their determination with HPLC. BMC Chem. 2019;13:59-69.
27. Hashemi SH, Keykha F. Application of the response surface methodology in the optimization of modified molecularly imprinted polymer based pipette-tip micro-solid phase extraction for spectrophotometric determination of nicotine in seawater and human plasma. Anal Methods. 2019;11:5405-12.

28. Kaykhaii M, Yavari E, Sargazi G, Khajeh-Ebrahimi A. Highly sensitive determination of bisphenol $A$ in bottled water samples by HPLC after its extraction by a novel Th-MOF pipette-tip micro-SPE. J Chromatogr Sci. 2020;23:373-82.

29. Shen Q, Gong L, Baibado JT, Dong W, Wang Y, Dai Z, Cheung HY. Graphene based pipette tip solid phase extraction of marine toxins in shellfish muscle followed by UPLC-MS/MS analysis. Talanta. 2013;116:770-5.

30. Hashemi SH, Ziyaadini M, Kaykhaii M, Keikha AJ, Naruie N. Separation and determination of ciprofloxacin in seawater, human blood plasma and tablet samples using molecularly imprinted polymer pipette-tip solid phase extraction and its optimization by response surface methodology. J Sep Sci. 2020;43:505-13.

31. Hashemi SH, Kaykhaii M, Keikha AJ, Sajjadi Z, Mirmoghaddam M. Application of response surface methodology for silver nanoparticle stir bar sorptive extraction of heavy metals from drinking water samples: a Box-Behnken design. Analyst. 2019;144:3525-32.

32. Hashemi SH, Kaykhaii M, Keikha AJ, Naruie N. Application of molecularly imprinted polymer pipette tip micro-solid phase extraction of nalidixic acid and acetaminophen from pills and seawater samples and their determination by spectrophotometry. Chem Pap. 2020;74:4009-23.

\section{Publisher's Note}

Springer Nature remains neutral with regard to jurisdictional claims in published maps and institutional affiliations.
Ready to submit your research? Choose BMC and benefit from:

- fast, convenient online submission

- thorough peer review by experienced researchers in your field

- rapid publication on acceptance

- support for research data, including large and complex data types

- gold Open Access which fosters wider collaboration and increased citations

- maximum visibility for your research: over 100M website views per year

At BMC, research is always in progress.

Learn more biomedcentral.com/submissions 